\title{
INVESTIGAÇÃO MICROSCÓPICA DA ESTRUTURA DO LEITE ADICIONADO DE POLISSACARÍDEOS
}

\author{
FABIANO FREIRE COSTA * \\ JAIME VILELA DE RESENDE ** \\ LUIZ RONALDO DE ABREU ***
}

\begin{abstract}
Este trabalho objetivou estudar e comparar por meio da técnica de microscopia eletrônica de varredura, os efeitos da adição de íons cálcio na microestrutura e qualidade de soluções modelo de leite em pó com e sem $\kappa$-carragena. Quatro amostras de leite adicionadas ou não de $\kappa$-carragena $(0,025 \%)$ e cloreto de cálcio $(4 \mathrm{mM})$ foram aquecidas $\left(65{ }^{\circ} \mathrm{C} / 30\right.$ minutos) e armazenadas por 24 horas em refrigerador a $4{ }^{\circ} \mathrm{C}$. Após 24 horas de descanso, as amostras foram congeladas $\left(-80^{\circ} \mathrm{C}\right)$ e submetidas ao processo de liofilização por 72 horas. Aadição de íons cálcio não diminuiu o tamanho dos agregados moleculares após o processo de liofilização em comparação com os agregados formados com leite puro. A presença de $\kappa$-carragena no leite após liofilização formou estrutura rígida caracterizada pelas interações entre a $\kappa$-carragena e as proteínas do leite. O filme formado com a adição de íons cálcio e $\kappa$-carragena apresentou a propriedade de adsorção de cristais. A liofilização constituiu passo importante no procedimento de preparo das amostras, o que gerou economia de tempo e custo no que diz respeito a todo o protocolo de eliminação de água da amostra, conhecido e aplicado rotineiramente antes da visualização por microscopia eletrônica de varredura.
\end{abstract}

* $\quad$ Bacharel e Licenciado em Química, Mestre e Doutor em Ciências dos Alimentos, Pós-Doutorado (PNPDEmbrapa), Professor Adjunto A, Departamento de Farmácia, Universidade Federal de Juiz de Fora (UFJF), Campus Avançado de Governador Valadares, MG (e-mail: fabianofreirecosta@gmail.com).

** Engenheiro Químico, Mestre em Ciências dos Alimentos, Doutor em Engenharia de Alimentos, Laboratório de Microestrutura e Engenharia de Alimentos, Departamento de Ciências dos Alimentos, Universidade Federal de Lavras (UFLA), Lavras, MG (e-mail: jvresende@ufla.br).

*** Zootecnista, Mestre em Ciências dos Alimentos, PhD em Food Science, Laboratório de Tecnologia do Leite e Produtos Lácteos, Departamento de Ciências dos Alimentos, UFLA, Lavras, MG (e-mail: Irabreu@ ufla.br). 


\section{INTRODUÇÃo}

O leite é constituído principalmente por proteínas (3,25\%), gorduras $(3,9 \%)$, água (87 \%) e outros componentes sólidos (5,5\%) que incluem lactose e sais minerais, embora exista a possibilidade de se encontrar mais de 100.000 espécies moleculares diferentes (WILLIAN, D'ATH e AUGUSTIN, 2005). As proteínas do leite encontram-se distribuídas nas diferentes frações de caseínas e soroproteínas. As caseínas representam cerca de $80 \%$ das proteínas totais do leite e são compostas essencialmente pela $\alpha_{\mathrm{s} 1}$-caseína, $\alpha_{\mathrm{s} 2}$-caseína, $\beta$-caseína e $\kappa$-caseína, que unidas pelos nanoclusters de fosfato de cálcio formam estrutura supramolecular, conhecida como micelas, cuja estabilidade tem sido estudada (FOX e MCSWEENEY, 1998). As soroproteínas representam cerca de $20 \%$ das proteínas totais do leite, sendo constituídas principalmente pela $\alpha$-lactalbumina, $\beta$-lactoglobulina, soro albumina e imunoglobulinas (DALGLEISH e MORRIS, 1988).

Soluções lácteas modelo, contendo estabilizantes e minerais, são utilizadas com o intuito de investigar e explicar os mecanismos e interações que podem ocorrer durante o processo de fabricação e estocagem de produtos em geral (REGAND e GOFF, 2006; LANGENDORFF et al., 2000). Os estabilizantes são substâncias hidrofílicas que se dispersam em solução como coloides. A maioria desses produtos, classificados como gomas ou hidrocoloides, é definida como qualquer polissacarídeo solúvel em água (extraído de vegetais terrestres, marinhos ou de micro-organismos) que pode sofrer modificações químicas para alcançar as características desejadas. Assim, são amplamente utilizados devido às suas características texturométricas, estruturais e funcionais, proporcionando estabilidade a emulsões, suspensões e espumas (FENNEMA, 1993).

As carragenas, utilizadas como estabilizantes para soluções lácteas (MARSHALL, GOFF e HARTEL, 2003), são polissacarídeos de cadeia longa com massa que varia de 100.000 a 1.000 .000 Daltons, sendo encontradas nas formas kappa $(\kappa)$, lambda $(\lambda)$ e iota ( $(1)$ carragena (HOSSAIN et al., 2001). A א-carragena forma gel em presença de cátions e essa capacidade de geleificação e suas propriedades físico-químicas dependem da quantidade e da disponibilidade dos íons metálicos envolvidos. Quando polieletrólitos, como a carragena, são combinados com íons mono ou polivalentes de cargas opostas formam hidrogel denominado ionotrópico. Os hidrogeis ionotrópicos se degradam, desintegram ou se dissolvem gradualmente graças às ligações de hidrogênio, forças iônicas e moleculares envolvidas nas interações entre os grupamentos negativos, presentes na estrutura molecular dos polissacarídeos com os metais (PRESTWICH et al., 1998). A principal função da $\kappa$-carragena consiste em limitar a separação de fases entre os polissacarídeos adicionados à solução que contém proteínas do leite. Todas as interações descritas acima são reversíveis e podem ser mudadas conforme a natureza física das moléculas pelas diferentes qualidades das ligações envolvidas e por meio de variações na temperatura, pH, aplicação de forças externas ou adição de solutos que possam competir com essas ligações (LANGENDORFF et al., 2000; SCHORSCH, JONES e NORTON, 2000; SPAGNUOLO et al., 2005; VEGA, DALGLEISH e GOFF, 2005).

A suplementação com íons cálcio em alimentos, principalmente em derivados lácteos, é praticada pela indústria para aumentar as condições nutricionais do produto e alcançar maior valor agregado. Estudos devem ser realizados para se investigar os efeitos das interações entre os suplementos adicionados e os ingredientes necessários para a produção de alimentos seguros e de qualidade. No intuito de entender os mecanismos e interações entre os componentes do sistema que forma o sorvete, este trabalho objetivou estudar e comparar mediante microscopia eletrônica de varredura os efeitos da adição de cálcio na microestrutura e qualidade de soluções modelo adicionadas de $\kappa$-carragena.

\section{MATERIAL E MÉTODOS}

\subsection{PREPARO DAS AMOSTRAS}

Preparou-se solução de leite em pó desnatado (15,4 \%) que foi dividida em quatro lotes. 
Ao primeiro lote foi adicionado $\kappa$-carragena $(0,025 \%)$ e cloreto de cálcio $(4 \mathrm{mM})$, o segundo lote recebeu apenas $\kappa$-carragena $(0,025 \%)$, ao terceiro adicionou-se cloreto de cálcio $(4 \mathrm{mM})$ e o quarto lote não recebeu aditivos (controle). As misturas foram aquecidas $\left(65^{\circ} \mathrm{C} / 30\right.$ minutos), armazenadas por 24 horas em refrigerador a $4{ }^{\circ} \mathrm{C}$ e congeladas $\left(-80^{\circ} \mathrm{C}\right.$ ) após 24 horas de descanso (ALVES, PASCHOLATI e LEITE, 2001; COSTA et al., 2008; ALVES et al., 2012).

\subsection{LIOFILIZAÇÃO}

As amostras congeladas em freezer $\left(-80^{\circ} \mathrm{C}\right)$ por 2 horas foram conduzidas ao liofilizador piloto (Liobras-L101). Após 72 horas, as amostras liofilizadas foram armazenadas em tubos falcon e armazenadas em geladeira a $-18^{\circ} \mathrm{C}$ (CAILLET et al., 2003).

\subsection{ANÁLISE POR MICROSCOPIA ELETRÔNICA DE VARREDURA}

\subsubsection{Montagem nos stubs}

As amostras liofilizadas foram coletadas com fita dupla face de carbono sobre suporte de alumínio - stubs (ALVES, PASCHOLATI e LEITE, 2001; ALVES et al., 2012).

\subsubsection{Metalização com ouro}

Os stubs montados com as amostras após liofilização foram recobertos com ouro em evaporador Bal-tec-SCDa50 (ALVES, PASCHOLATI e LEITE, 2001; ALVES et al., 2012).

\subsubsection{Visualização}

Após metalização, os stubs foram visualisados em microscópio eletrônico de varredura (Mevleo-Evo40xvp), com tensão de aceleração de 20 Kv (ALVES, PASCHOLATI e LEITE, 2001; ALVES et al., 2012).

\section{RESULTADOS E DISCUSSÃO}

Na Figura 1 é possível observar os grânulos do leite liofilizado aglomerados, parecendo fundidos uns aos outros e variando em tamanho e morfologia. A cada grânulo de diferente tamanho observado na eletromicrografia de varredura pode-se atribuir a existência de milhares de partículas coloidais aglomeradas e fundidas entre si formando estrutura maior, composta pela aglomeração das micelas de caseínas desidratadas.

As eletromicrografias de varredura (Figura 2) mostram as soluções modelo adicionadas ou não de $\kappa$-carragena e cloreto de cálcio após a liofilização. De acordo com a Figura $2 \mathrm{~A}$ verifica-se a formação de grânulos aglomerados de vários tamanhos e morfologia com aparência de fundidos uns aos outros. A cada grânulo de diferente tamanho observado através da eletromicrografia de varredura é possível atribuir a existência de milhares de partículas coloidais aglomeradas e fundidas entre si formando uma estrutura maior, como observado na Figura 2A. Esses grânulos, de acordo com Fox e McSeeney (1998), são as micelas de caseínas desidratadas, aglomeradas e constituídas por submicelas. Cada submicela apresenta em sua estrutura as proteínas do leite $\left(\alpha_{\mathrm{s} 1}{ }^{-}\right.$caseína, $\alpha_{\mathrm{s} 2}{ }^{-}$ caseína, $\kappa$-caseína e $\beta$-caseína) estabilizadas pelos nanoclusters de fosfato de cálcio, os quais não foram observados por essa técnica. A adição de íons cálcio (Figura 2B) não modificou aparentemente a estrutura e o tamanho dos aglomerados, quando se confrontam as Figuras 2A e 2B, embora seja bastante discutido que na presença de íons cálcio ocorre diminuição das micelas de caseína em relação às amostras de leite que apresentam quantidades menores desse mineral (DALGLEISH e CORREDIG, 2012). 

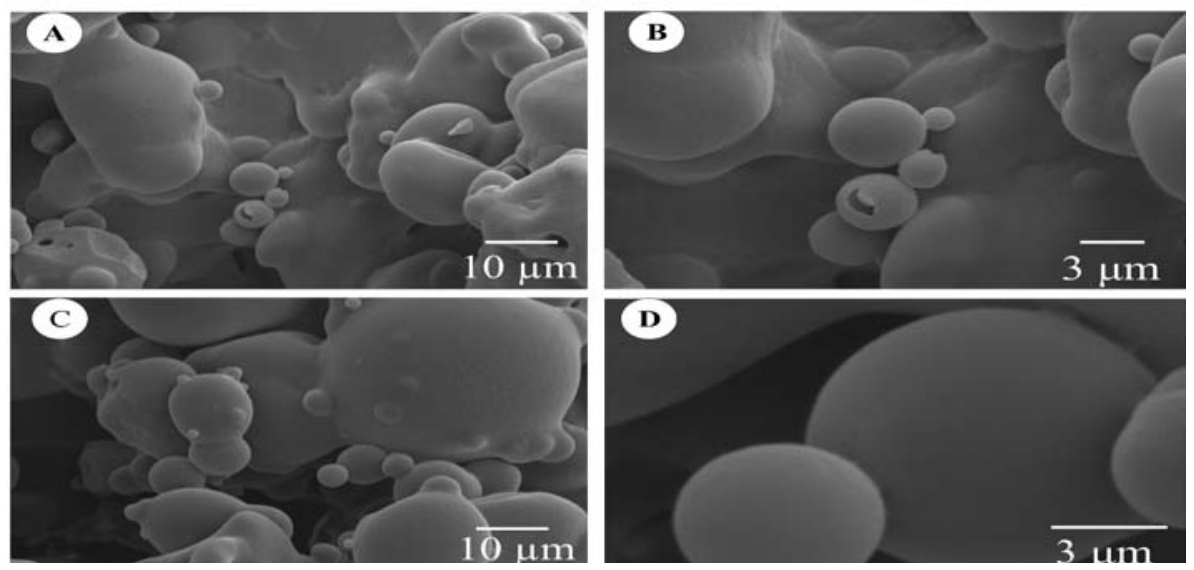

\section{FIGURA 1 - MICROESTRUTURA DE LEITE LIOFILIZADO UTILIZANDO A TÉCNICA DE MICROSCOPIA ELETRÔNICA DE VARREDURA (A, B, C e D)}

Grânulos de diferentes tamanhos e formas de aglomeração (A, B, C e D).

O efeito da adição de íons cálcio em soluções lácteas foi discutido por Costa et al. (2008). Quando íons cálcio são adicionados ao leite, as micelas de caseína desidratam devido à competição que ocorre entre a água de hidratação presente nas proteínas lácteas e os átomos de cálcio. Com a desidratação, as micelas de caseína ficam mais compactadas devido à diminuição do seu tamanho ocasionada pela liberação da $\beta$-caseína para fora dos aglomerados. A modificação das propriedades físico-químicas das micelas pode causar danos, como instabilidade e separação de fases em bebidas lácteas em geral. As carragenas são utilizadas nas emulsões lácteas justamente para evitar a separação entre fases e conferir maior estabilidade durante seu processamento e estocagem (TURNIER e KRUIF, 2002; ZHANG e GOFF, 2004; TREJO et al., 2011).
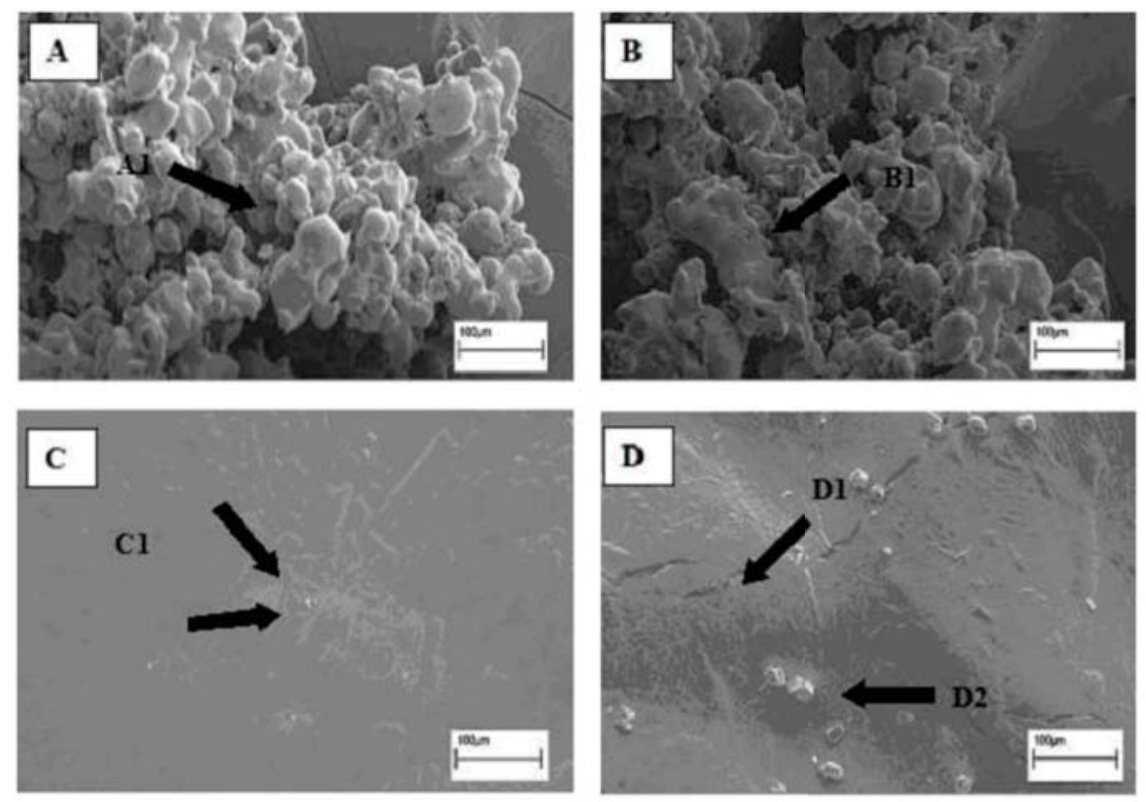

FIGURA 2 - ELETROMICROGRAFIA DE VARREDURA (A) LEITE PURO LIOFILIZADO, (B) LEITE ADICIONADO DE CÁLCIO, (C) LEITE ADICIONADO DE K-CARRAGENA, (D) LEITE ADICIONADO DE K-CARRAGENA E CÁLCIO

A1 = micelas de caseína; $B 1$ = micelas de caseína fundidas; $C 1$ = cristais de cloreto de cálcio; $D 1$ = fendas ou trincas; D2 = cristais de cloreto de cálcio depositados. 
As Figuras $2 \mathrm{C}$ e 2D mostram as amostras liofilizadas adicionadas de $\kappa$-carragena (2C) e de $\kappa$-carragena e cálcio (2D). Durante a manipulação para montagem nos stubs foi observado que as amostras adicionadas apenas de leite e $\kappa$-carragena formaram estrutura polimérica bastante rígida, porém quebradiça. Já as amostras adicionadas de к-carragena, leite e cálcio após a liofilização apresentaram estrutura polimérica maleável. De acordo com as eletromicrografias, a topografia do polímero adicionado de $\kappa$-carragena na ausência ou na presença de cálcio diferenciou-se apenas pela presença de trincas e cristais de cloreto de cálcio adsorvidos na superfície da estrutura polimérica (Figura 2D). A simplificação da metodologia apresentada neste artigo foi eficiente na etapa de preparo das amostras, gerando economia de reagentes e do tempo gastos rotineiramente antes da visualização de amostras biológicas por microscopia eletrônica de varredura. Tais resultados mostram também que não houve problema durante a geração das imagens, obtendo-se eletromicrografias com excelente qualidade visual.

Os resultados encontrados podem ser explicados pelas interações que ocorrem entre os componentes: caseína/ $\kappa$-carragena/cálcio. De acordo com a literatura, as carragenas em geral interagem eletrostaticamente com as micelas de caseína quando adicionadas ao leite (DALGLEISH e CORREDIG, 2012). Nessas interações estão envolvidos átomos de cálcio, fósforo e moléculas de água. Com o processo de liofilização, a água presente nessas interações e a água que constitui todo sistema é sublimada ocasionando a fusão entre as estruturas proteicas presentes no leite e as carragenas, formando estrutura rígida e quebradiça. Na presença de cloreto de cálcio, as interações entre as micelas de caseína/к-carragena foram prejudicadas. A к-carragena, por estar em solução carregada negativamente, apresenta forte atração pelos íons cálcio que são carregados positivamente. Com essa interação predominantemente de natureza iônica, parte do mineral se liga com as moléculas de $\kappa$-carragena formando biofilme com capacidade para adsorver cristais de cloreto de cálcio (como observado na Figura 2D). A liofilização permitiu eliminar grande parte da água presente no meio, o que não interferiu na qualidade visual das amostras analisadas (LANGENDORFF et al., 2000; SCHORSCH, JONES e NORTON, 2000; SPAGNUOLO et al., 2005; VEGA, DALGLEISH e GOFF, 2005).

\section{CONCLUSÃO}

A adição de íons cálcio não diminuiu o tamanho dos agregados moleculares após o processo de liofilização em comparação com os agregados formados apenas com leite puro. A presença de $\kappa$-carragena no leite após liofilização formou estrutura rígida, caracterizada pelas interações entre a $\kappa$-carragena e as proteínas do leite. $O$ filme formado com a adição de íons cálcio e $\kappa$-carragena apresentou a propriedade de adsorção de cristais. A simplificação do preparo das amostras para visualização pela técnica de microscopia eletrônica de varredura foi suficiente para mostrar os resultados apresentados neste trabalho. A liofilização constituiu passo importante no procedimento de preparo das amostras, o que gerou economia de tempo e custo no que diz respeito a todo o protocolo de eliminação de água da amostra, conhecido e aplicado rotineiramente antes da visualização por microscopia eletrônica de varredura.

\section{ABSTRACT \\ MICROSCOPIC INVESTIGATION OF THE STRUCTURE OF MILK ADDED POLYSACCHARIDES}

This study aimed to investigate and compare the effects of calcium and $\kappa$-carrageenan addition on microstructure and quality of model solutions using the technique of scanning electron microscopy. Four samples of milk with or without $\kappa$-carrageenan $(0.025 \%)$ and calcium chloride $(4 \mathrm{mM})$ were heated $\left(65^{\circ} \mathrm{C} / 30\right.$ minutes $)$ and stored for 24 hours in a refrigerator at $4{ }^{\circ} \mathrm{C}$. After 24 hours, the samples were frozen $\left(-80^{\circ} \mathrm{C}\right)$ and than lyophilizated during 72 hours. The addition of calcium ions did not decrease the size of the molecular aggregates after lyophilization as compared to aggregates formed only with milk. The presence of $\kappa$-carrageenan in milk after lyophilization formed a rigid structure characterized by interactions between $\kappa$-carrageenan and milk proteins. The film formed by adding calcium ions and $\kappa$-carrageenan has the property of adsorbing crystals. Lyophilization was an important step on the preparation of the samples reducing time and costs in regard to samples' water elimination protocol, well known and routinely applied before scanning electron microscopy. 


\section{REFERÊNCIAS}

1 ALVES, E.; LUCAS, G.C.; POZZA, E.A.; ALVES, M.C. Scanning electron microscopy for fungal sample examination. In: GUPTA, V.K. et al. (eds.) Laboratory protocol in fungal biology: current methods in fungi biology. New York: Springer, 2012.

2 ALVES, E.; PASCHOLATI, S.F.; LEITE, B. Formation of bacterial biofilms on the surface of polystyrene: a methodology for the scanning electron microscope. In: CONGRESSO DA SOCIEDADE BRASILEIRA DE MICROSCOPIA E MICROANÁLISE, 18., 2001, Águas de Lindóia, SP. Anais... São Carlos: SBMM, 2001. p. 155-156.

3 CAILLET, A.; COGNE, C.; ANDRIEU, J.; LAURENT, P.; RIVOIRE, A. Characterization of ice cream structure by direct optical microscopy. Influence of freezing parameters. Food Science and Technology, San Diego, v.36, n.6, p.743-749, 2003.

4 COSTA, F.F.; RESENDE, J.V.; ABREU, L.R.; GOFF, H.D. Effect of calcium clhoride adittion on ice cream structure and quality. Journal of Dairy Science, Champaign, v.91, n.6, p.2165-2174, Jun. 2008.

5 DALGLEISH, D.G.; MORRIS, E.R. Interactions between carrageenans and casein micelles: electrophoretic and hydrodynamic properties of the particles. Food Hydrocolloids, Oxford, v.2, n.3, p.311-320, 1988.

6 DALGLEISH, D.G.; CORREDIG, M. The structure of the casein micelle of milk and its changes during processing. Annual Reviewing Food Science and Technology, v.3, p. 449-467, 2012.

7 FENNEMA, O.R. Química de los alimentos. 2. ed. Zaragoza: Acribia, 1993.

8 FOX, P.F.; MCSWEENEY, P.L.H. Dairy chemistry and biochemistry. London: Blackie Academic \& Professional, 1998. $487 \mathrm{p}$.

9 HOSSAIN, K.S.; MIYANAGA, K.; MAEDA, H.; NEMOTO, N. Sol-gel transition behavior of pure iota-carrageenan in both salt-free and added slat states. Biomacromolecules, Washington, v.2, p.442-449, 2001.

10 LANGENDORFF, V. et al. Effects of carrageenan type on the behavior of carrageenan/milk mixtures. Food Hydrocolloids, v.14, p.273-280, 2000.

11 MARSHALL, R.T.; GOFF, H.D.; HARTEL, R.W. Ice cream. $6^{\text {th }}$ ed. New York: Kluwer Academic, 2003.

12 PRETSWICH, G.D.; MARECAK, D.M.; MARECAK, J.F.; VERCRUYSSE, K.P.; ZIEBELL, M.R. Controlled chemical modification of hyaluronic acid. Journal of Controlled Release, Amsterdam, v.53, n.1-3, p. 93-103, Apr. 1998.

13 REGAND, A.; GOFF, H.D. Ice recrystallization inhibition in ice cream as affected by ice structuring proteins from winter wheat grass. Journal of Dairy Science, Champaign, v.89, n.1, p.49-57, Jan. 2006.

14 SCHORSCH, C.; JONES, M.G.; NORTON, I.T. Phase behavior of pure micellar casein/K-carrageenan systems in milk salt ultrafiltrate. Food Hydrocolloids, Oxford, v.14, n.4, p.347-358, Jul. 2000.

15 SPAGNUOLO, P.A.; DALGLEISH, D.G.; GOFF, H.D.; MORRIS, E.R. Kappa-carrageenan interactions in systems containing casein micelles and polysaccharide stabilizers. Food Hydrocolloids, Oxford, v.19, n.3, p.371-377, May 2005.

16 TREJO, R.; DOKLAND, T.; JURAT-FUENTES, J.; HARTE, F. Cryo-transmission electron tomography of native casein micelles from bovine milk. Journal of Dairy Science, Champaign, v.94, n.12, p.5770-5775, Aug. 2011.

17 TURNIER, R.; DE KRUIF, C.G. Stability of casein micelles in milk. Journal of Chemical Physics, v. 117, n.3, p.12901295, Jul. 2002.

18 VEGA, C.; DALGLEISH, D.G.; GOFF, H.D. Effect of $\mathrm{k}$-carrageenan addition to dairy emulsions containing sodium caseinate and locust bean. Food Hydrocolloids, Oxford, v.19, n.2, p.187-195, Mar. 2005.

19 WILLIANS, R.P.W.; D'ATH, L.; AUGUSTIN, M.A. Production of calcium-fortified milk powders using soluble calcium salts. Lait, Paris, v.85, n.4-5, p.369-381, Jul./Oct. 2005.

20 ZHANG, Z.; GOFF, H.D. Protein distribution at air interfaces in dairy foams and ice cream as affected by casein dissociation and emulsifiers. International Dairy Journal, Oxford, v.14, n.7, p.647-657, Jul. 2004.

\section{AGRADECIMENTOS}

Os autores agradecem à Fundação de Amparo a Pesquisa do Estado de Minas Gerais (FAPEMIG, 12042/09) pelo auxílio financeiro, à Coordenação de Aperfeiçoamento de Pessoal (CAPES, PNPD 02858/09-6) pelo fornecimento da bolsa de Pós-Doutoramento a Fabiano Freire Costa. 